\title{
The Effect of an Intensive English Program on the Vocabulary Size of Lebanese English Foreign Learners
}

\author{
Reema Abouzeid ${ }^{1}$ \\ ${ }^{1}$ Department of English and Translation, Faculty of Humanities, Notre Dame University, Louaize, Lebanon \\ Correspondence: Reema Abouzeid, Department of English and Translation, Faculty of Humanities, Notre Dame \\ University, Louaize, Lebanon. E-mail: rabouzeid@ndu.edu.lb
}

Received: June 19, 2018 Accepted: August 23, 2018 Online Published: September 11, 2018

doi:10.5539/ijel.v8n6p281 URL: https://doi.org/10.5539/ijel.v8n6p281

\begin{abstract}
The research concerning intensive programs in general has yielded conflicting results and as such, whether or not such time-shortened courses are effective in achieving their learning objectives is a matter of controversy. This study hopes to contribute to the current body of research available and perhaps aid in clearing the uncertainty surrounding such compact programs in a foreign language context by evaluating the effectiveness of one IEP at an English-medium university in Lebanon through the construct of vocabulary size. The vocabulary size of 100 English as a Foreign Language (EFL) learners enrolled in an Intensive English Program (IEP) was measured pre and post instruction using the New Vocabulary Levels test (NVLT). Test results were examined and compared using a dependent samples t-test to determine the effectiveness of the IEP in improving students' vocabulary size. Results revealed that across the NVLT's 6 receptive vocabulary lists $(1000,2000,3000,4000$, and 5000 most frequent words in addition to the Academic Word List), students showed a statistically significant improvement on the post test $(\mathrm{p}=0.000<0.05)$, endorsing the effectiveness of IEP in a foreign language context in enhancing students' receptive vocabulary size. This study concludes with practical implications for EFL IEP teachers and syllabus designers.
\end{abstract}

Keywords: English as a Foreign Language (EFL), Intensive English Program (IEP), New Vocabulary Levels Test (NVLT), academic vocabulary, word frequency lists

\section{Introduction}

\subsection{Intensive Programs}

Intensive courses are commonly referred to as accelerated, time-shortened and compressed courses (Burton \& Nesbit, 2002; Scott \& Conrad, 1992; Wlodkowski, Iturralde-Albert, \& Mauldin, 2000). They are programs "in which students participate in a higher number of classes in a shorter period (Mukundan, Mahvelati, \& Nimehchisalem, 2012, p. 1)" with little or no sacrifice to educational quality.

\subsubsection{The Effectiveness of Intensive Programs}

Several studies have investigated the effectiveness of intensive programs and reported positive results, including greater achievement of learning outcomes than regular, more traditional classes (Bédard \& Thomas, 2010; Burton \& Nesbit, 2002; Daniel 2000; Geltner \& Logan, 2001; Grant, 2001; Jonas \& Weimer, 1999; Kops, 2014; Martin \& Culver, 2007; Mukundan, Mahvelati \& Nimehchisalem, 2013; Scott \& Conrad, 1992; Spade \& Lightbrown, 1994).

Specific to second and foreign language intensive programs, Buzash's (1994) study concluded that high school students in an intensive French course improved substantially in language proficiency equivalent to one college semester. Similarly, Spade and Lightbrown (1994) concluded that English as a Foreign Language (EFL) students in the intensive English program (IEP) produced superior results compared to students enrolled in the traditional class format. Freed, Segalowitz, and Dewey (2004), in a comparison of intensive French classes of 17.5 hours per week with traditional French classes of 204 hours per week, found that the intensive students exhibited more significant gains. Yet another study concluded that students of the IEP (18-20hrs/week) were more fluent, more confident and gained significantly more than those students in the traditional, non-intensive $(1 \mathrm{hr} /$ week) class (White \& Turner, 2005). Some researchers have reported that IEPs for EFL students can be "more effective than distributed practice in classroom learning especially in the case of second/foreign languages (Serrano \& Munoz, 
2007, p. 319)." A more recent study with L2 participants enrolled in a 10 -week IEP concluded that this instructional format had "positive and encouraging" findings with students making substantial improvements in their English proficiency (Ping, 2014). Similarly, a study investigating the effect of an IEP on a group of Malaysian ESL students found that intensive courses were beneficial and students were able to "achieve real gains" (Mukundan, Mahvelati \& Nimehchisalem, 2012, p. 6). Other studies confirming the effectiveness of intensive programs in the field of second/foreign language include Carson and Kuehn (1992), Hong-Nam and Leavell (2006), Jacques-Bilodea (2010), Nagano (1995) and Raymond (1995).

In a comprehensive review of recent literature, Tatum (2010) states that there is significant evidence proving the effectiveness of accelerated education. In studies that have compared the results of intensive programs with the more traditional forms of education, "very few studies report superior outcomes for the traditional method (p. 48)." He proceeds to state that "quite frequently the literature shows that the accelerated format produces better learning and achievement than the traditional format (p. 48)".

\subsubsection{The Ineffectiveness of Intensive Programs}

On the other hand, studies (Bateson, 1990; Gallow \& Odu, 2009; Nasiri \& Shokrpour, 2012) have highlighted the ineffectiveness of intensive programs, noted several disadvantages, and thus raised doubts concerning their efficacy. Carrington (2010) and Bateson (1990) both argue that learning is enhanced in traditional, non-intensive programs and that students actually performed significantly better. A study comparing students' performance in intensive and non-intensive English reading comprehension classes in an EFL university context in Iran found that students of various majors in regular two-day a week English courses achieved significantly more than those in intensive scheduling (Nasiri \& Shokrpour, 2012). There is also the concern that in intensive programs students may not be able to digest compressed materials and condensed knowledge, highlighting the possibility of students feeling frustrated, fatigued and stressed because of the lack of time to review and reread old material before new material is presented (Henbery, 1997).

With the research on the effectiveness of intensive courses providing inconsistent results, in an EFL context such as Lebanon, where IEPs are offered at every English-medium university, such discrepancies leave little certainty to fall back on. Compounding the problem further, IEPs in the Middle East in general and in Lebanon in particular have received very little attention with a severe lack of evaluative studies. Other than Nasser and Goff-Kfouri (2008) who investigated whether or not the intensive and remedial English courses at the same university of this study impact subsequent academic attainment in English and the general academic performance by studying the correlation between overall Grade Point Average (academic performance) for those who experienced intensive instruction relative to the number of intensive and remedial courses taken, such programs in Lebanon remain under investigated. With the need for IEPs only increasing, evaluating IEPs and assessing their effectiveness is a research gap that needs to be filled. Nasser and Goff-Kfouri (2008) make the crucial point that "in the absence of such evaluative and operative studies, one cannot establish what these programs actually accomplish (p. 88).” This study hopes to contribute to filling this gap.

\subsection{Intensive English Programs in Lebanon}

In Lebanon, the need for effective IEPs is growing for two main reasons: firstly, more and more EFL (French-educated) students are opting to attend English-medium universities with a proficiency in English below that which is required. Secondly, English-medium universities are adopting an open-doors policy. These two causes are discussed further.

Lebanon is predominantly a trilingual country with Arabic, French, and English, spoken widely. In 1994, when the new National Language Curriculum was implemented, all schools were required to teach a foreign language in addition to a second language. As such, Arabic, English and French were all widely used and schools predominantly had English as the third language and French as the second. Not only is English in Lebanon a third language but for most students, even at the university level, exposure to English outside the classroom is limited and thus so are the opportunities to use English, which is a major barrier inhibiting learners' ability and opportunity to develop the required proficiency (Al-Khatib, 2013). Even if students attend an English-medium university, Arabic is the language they resort to for interaction outside the classroom (Bacha \& Bahous, 2011). Nicolas and Annous' (2013) study at a private English-medium university Lebanon describe the context as one in which students "by and large resort to Arabic rather than English in their social interactions on campus and in their dealings with family and community. English is viewed as a language to use for some university work and is not the default language in the overwhelming majority of cases (p. 173)."

As a result of the lack of a conducive learning environment for English proficiency, the demand for IEPs surfaces when EFL students choose to attend an English-medium university: Their English proficiency 
(according to the results of the English placement test designed to assess their competency level) is inadequate for university study (Al-Khatib, 2013). Students who do not meet the minimum entry requirements are placed in an IEP to help prepare them for their academic coursework. With EFL students who were raised in Arabic-speaking households and who went to French-speaking schools comprising the majority of the student body at English-medium universities, IEPs are now offered at every such university.

\subsubsection{The Shift from French to English}

There are several reasons why EFL students are opting to study at English universities. Shaaban and Ghaith's (2002) ethnographical study on 176 randomly chosen Lebanese university students concerning their perceptions of the vitality of the three languages found that the majority consider Arabic essential for "national identity and communication with family, French for entertainment and elementary education, and English for higher studies, technology and commerce (p. 568)." More recent students have confirmed this cultural belief. For example, Diab's (2006) study on 284 university students in Lebanon found that most students considered English as more important than French and concluded that they are highly instrumentally motivated to learn English. Likewise, Sinno's (2008) study at an English-medium university highlighted that a particular source of extrinsic motivation was English's potential to increase work opportunities on an international level. Furthermore, El-Dakhs (2015) confirms that a main requirement for employment in the Arab world, where many graduating students go to seek employment, is English and so students' interest in English and choice to study in English "comes naturally....to achieve a reasonable standard of living (p. 60)."

\subsubsection{An Open-Doors Policy}

The second reason for increasing demand for IEP pertains to university policy and financial motivations. As Davies (2006) aptly states "whether we like it or not, the university is now a corporate entity (p. 19)" and this business approach to education means that maintaining high enrollment rates is paramount. Nasser and Goff-Kfouri (2008) highlight this trend in Lebanon and state that with the current "open admission policy and enterprising international higher education system, universities now seek students rather than students seek universities (p. 87)." The adoption of such a business-like approach to education has inevitably resulted in more lenient entrance requirements. That is, rather than jeopardize enrolment numbers by turning away students who do not perform up to the required standard on the English entrance exams, they are placed in IEPs with the goal of enhancing their proficiency in English to the level necessary to continue their studies in English with academic success.

With the presence of these two compounding factors of low-proficiency EFL learners opting to study at English-medium universities and an open-doors policy adopted by universities, the challenge of maintaining academic standards while increasing enrolment has been introduced (Davies, 2006; Feast, 2002). This has in turn increased the need for IEPs; students are accepted and placed in the intensive program. Given that "language proficiency is a critical factor in academic success (Ciccarelli, 2001, p. 3)" and that "nobody would argue the English language proficiency has no role to play in academic achievement (Hill, Storch \& Lynch, 1999, p. 63)" the availability of IEPs and their ability to meet the set learning objectives is paramount. But what's even more important is assessing these programs to determine if they are achieving their objectives.

In light of the fact that in Lebanon there is little consensus of what these IEPs are actually achieving and their effectiveness (Nasser \& Goff-Kfouri, 2008), this study hopes to contribute to answering these questions and continue the discussion that Nasser and Goff-Kfouri (2008) began as since then, no study has assessed the effectiveness of the current IEP. The motivation for this study stems from my own personal observation that despite completing the IEP, a large number of learners struggle in the subsequent remedial courses and general English courses. This sentiment is echoed by many fellow faculty members who commonly complain about intensive students' inability to perform at the expected standard in courses post IEP because their English is below the standard that they consider necessary for successful academic study. As a result, faculty members are facing challenges in the classroom and struggling to maintain the academic pace and rigor required in the following English courses.

\subsection{Literature Review}

\subsubsection{The Importance of Vocabulary Acquisition for Language Proficiency}

The high correlation between vocabulary knowledge and EFL/ESL learner performance is supported by a large body of research and it has been widely acknowledged that vocabulary knowledge is fundamental to all language use (Schmitt, Cobb, Horst, \& Schmitt, 2015). Wilkins (1972) clearly affirmed many years ago "without vocabulary, nothing can be conveyed (p. 111)." Likewise, Vermeer (1992) maintained that "knowing words is 
the key to understanding and being understood (p. 147)" Research is continuously reaffirming the correlation between vocabulary size and proficiency in English and endorsing this integral relationship between developing a learner's vocabulary knowledge in order to develop his/her performance in the target language in general. For example, Beglar and Hunt (2005) suggested that "vocabulary acquisition is a crucial, and in some cases, the central component in successful foreign language acquisition" (p. 7), while Nation (2006) confirmed that with a rich vocabulary, other skills are easier to perform. Similarly, Malvern, Richards, Meara and Milton (2008) state that "vocabulary knowledge is indispensable to acquire grammar and to trigger the setting of universal grammatical parameters (p. 270)". All of this research confirms Ellis' Lexical Learning Hypothesis (1997) which asserts that knowledge of vocabulary is what "drives learning in all other aspects of language (Milton, 2013, p. $67)$." Thus, it is evident that the role vocabulary acquisition plays is central and of utmost importance in the acquisition of a language.

\subsubsection{Vocabulary Acquisition in Terms of Vocabulary Size}

Given the importance of vocabulary acquisition in improving competency in a second or foreign language, increasing the size of a learner's vocabulary is essential for successful use of the language and, in the case of students, for academic success (Folse, 2010). Vocabulary size, also referred to as vocabulary breadth, is the number of words a learner has at least some minimum superficial knowledge of (Nation, 2001; Meara, 1996). Vocabulary depth, on the other hand, is knowledge of "how these words may work, their nuance of meaning and subtleties of combination (Milton, 2010, p. 219)". Staehr (2008) concluded that it is the construct of vocabulary size that is crucial for determining a student's ability to perform in the four language skills and Milton (2013) concisely summarizes Staehr's (2008) findings stating that "vocabulary size may be the determinant factor, pre-eminent among other factors which may be at work in performing in and through a foreign language (p. 72)." Numerous other experts in the field note that vocabulary breadth is an ideal, efficient and reliable predictor and measure of general proficiency and learner competence in a foreign and second language (Alderson, 2005; Cobb, 2007; Decarrico, 2001; Gao, 2003; Meara, 1996; Milton, 2010; Milton, Wade, \& Hopkins, 2010; Nation, 1990; Read, 1998; Schmitt et al., 2015; Schoonen, 2010). Additionally, Milton (2013) notes that "a single measure of vocabulary knowledge is likely, by itself, to be a good indicator of skill and level in a foreign language (p. 72)." Similarly, Read (2007) states that testing the construct of vocabulary size can serve as a "valuable means (p. 121)" to assessing the students' linguistic proficiency overall. Also due to the high correlation of vocabulary size with scores on general proficiency test, vocabulary size is also often used as a proxy for general proficiency in language acquisition research (Alderson, 2005). In the same vein, Schoonen (2010) confirms that vocabulary size is a good predictor of performance overall in the target language and that it can explain the variance among students' performance. Milton et al., (2010) concluded form their study that up to $50 \%$ of the variation in students' grades is due to difference in students' vocabulary size, further highlighting the essentiality of vocabulary breadth. Harji, Balakrishnan, Bhar and Letchumanan (2015) note that students' academic progress may be affected with a limited vocabulary size as they will fail to comprehend what they read. Nation and Beglar (2007) also support vocabulary assessment as a tool for monitoring development, while Webb and Chang (2012) state that by examining which words and how many words students learn, the effectiveness of a program may be determined.

In accordance with all these testimonies and assertions, in the present study, the effectiveness of the IEP in enhancing students' proficiency in the English language to adequately prepare them for the next English course is assessed in terms of examining the change in students' vocabulary breadth. Given that without vocabulary breadth, vocabulary depth cannot be developed (Milton, 2013, p. 61), that as vocabulary breadth increases, vocabulary depth will naturally increase (Vermeer, 2001), and that "only at the most advanced levels will development of vocabulary depth be relevant (Milton, 2013, p. 64)", this study is limited to examining students' vocabulary size.

\subsubsection{Lexical Coverage and Vocabulary Breadth}

A large vocabulary size is essential for effective interaction in a foreign language (Gallego \& Llach, 2009; Milton, 2013). As such, researchers have quantified the number of words necessary to comprehend texts in the target language. Laufer (1992) suggested that adequate comprehension of a text in English requires no more than one unknown word in every 20 words, equating to a $95 \%$ lexical coverage, where coverage is the percentage of words that a reader has receptive knowledge of (Laufer \& Ravenhorst-Kalovski, 2010). Having receptive knowledge of a word means that when a word that occurs in the speech or writing of others, it can be called to mind for comprehension (Milton, 2013). Thus, 95\% coverage means that the reader has receptive knowledge of $95 \%$ of the running tokens of a text. In order for learners to apply their first language (L1) reading strategies, this $95 \%$ lexical threshold in reading is necessary (Laufer, 1997). Numerous studies have supported this $95 \%$ 
threshold for successful unassisted reading (Clay 1991; Hayashi 2002; Honig 2001; Juel 1994; Laufer 1989 and 1992; Nation 2001; Read 2000; Schmitt and McCarthy 1997; Tono 1997). Several other studies confirm that although comprehension of a text can be successfully achieved with a $95 \%$ lexical coverage, a $98 \%$ lexical coverage would put the learner in a better position to accurately guess the $2 \%$ of unknown words, as will as make reading more pleasurable (Cody et al., 1993; Hirsch and Nation, 1992). These findings would explain why Matsuoka and Hirsch (2010) state that 95\% lexical coverage of texts covered in class is sufficient for students because they are in a learning environment where assistance is provided. Thus, students in a university setting require a lexical coverage of $95 \%$ for adequate comprehension.

\subsubsection{Word Family Frequency Lists}

How many words students need to have receptive knowledge of in order to achieve a 95\% lexical coverage has been determined by corpus driven studies of vocabulary in both spoken and written discourse. Nation's (2012) British National Corpus / Corpus of Contemporary American English (BNC/COCA) word lists are 25 word-family frequency lists with each list comprising 1,000 word families based on frequency and range. The BNC is a 100 million-token corpus consisting of $90 \%$ written text and $10 \%$ spoken text and the COCA is a 450 million corpus of American English equally divided between the genres of spoken, fiction, popular magazines, newspapers and academic journals. The word family construct comprises a headword, its inflected forms and closely derived forms (Nation, 2001). For example, the word family of abbreviate contains the following members: abbreviate, abbreviates, abbreviated, abbreviating, abbreviation, abbreviations. The words that a part of a word family "would be perceived as the same words for the receptive skills of listening and reading (Nation, 2006, p. 67). If a learner knows at least one member of the word family, then "using knowledge of the most common and regular of the English word-building devices (Nation 2006 p. 67)", s/he can understand the other members of the word family. Coxhead (2000) also notes that "comprehending regularly inflected or derived members of a family does not require much effort by learners if they know the base word and if they have control of basic word processes (p. 218)." Even students of low English proficiency do indeed hold some control of world building devices and can identify formal and meaning-based relationships between regularly affixed members of a word family such that knowledge of a word can be assumed to mean knowledge of a word family (Beglar, 2010; McLean \& Kramer, 2015).

These word family frequency lists are based on the frequency effect of vocabulary acquisition: learners of a language, native or non-native, acquire vocabulary which occurs more frequently in the language before acquiring vocabulary which occurs less frequently (Nation, 2006). Kremmel (2016) reiterates this, stating that "the more frequent a word occurs in discourse, the more important it is for language use, and the more likely it is to be learnt at an early stage (p. 979)." Higher frequency words are acquired faster and also processed faster than lower frequency words (Read, 1998). Furthermore, in reference to the powerful effect of frequency in the learning of foreign language vocabulary, Milton (2009) states that "the importance of frequency in vocabulary learning is as near to a fact as it is possible to get in L2 acquisition" (p. 242).

Several studies have confirmed this. The vocabulary size and pattern of progression of the French foreign language participants in Milton's (2006) study acquired the more frequent words first such that "each successive frequency band displays a score lower than its predecessor and the frequency profile overall is as expected (p. 193)." Fan (2001) also had results in line the with frequency effect. The 1076 students from seven different tertiary institutions in Hong Kong showed decreasing vocabulary knowledge as frequency decreased and the pattern of acquisition of receptive vocabulary was such that knowledge of lower frequency words was considerably lower than that of the higher frequency words. Li and MacGregor (2010) measured the English receptive vocabulary size of Chinese university students and found that students had mastered the higher frequency words $(2,000$ and 3,000), but not the lower frequency words (5,000). Also, Merikivi and Pietilä (2014) in a study of 330 Finnish schools students found that students' passive vocabulary knowledge decreased systematically as word frequency decreased.

Knowledge of the first $1,000(1 \mathrm{k})$ most frequently occurring word families alone provides a lexical coverage of $78-81 \%$ (Nation, 2006). These words occur so frequently that they make up the majority of running words in discourse and "clearly do the bulk of the work in English (Schmitt \& Schmitt, 2014, p. 485)." Knowledge of the second 1,000 most frequently occurring word families (2k) only provides an additional lexical coverage of $8-9 \%$, which clearly demonstrates the value of the highest frequency words of the $1 \mathrm{k}$ to learners. Knowledge of the third most frequently occurring 1,000 word families (3k) provides an additional 3-5\% lexical coverage, and although this additional coverage is essential for a student to reach the $95 \%$ threshold, these slightly lower frequency words do not have the same impact on language learning as the $1 \mathrm{k}$. The following table shows the decreasing lexical coverage provided as vocabulary becomes less frequent. Given that the fourth 1,000 word 
families and the fifth 1,000 word families together provide a lexical coverage of 3\%, Schmitt and Schmitt (2014) note that although there is no clear cut-off point that, high frequency vocabulary includes the most frequent 1-3,000 word families.

Table 1. Vocabulary size and written text coverage (Nation, 2006, p. 79)

\begin{tabular}{ll}
\hline Word families & Approximate written coverage $(\%)$ \\
\hline $1^{\text {st }} 1,000$ & $78-81$ \\
$2^{\text {nd }} 1,000$ & $8-9$ \\
$3^{\text {rd }} 1,000$ & $3-5$ \\
$4^{\text {th }}-5^{\text {th }} 1,000$ & 3 \\
$6^{\text {th }}-9^{\text {th }} 1,000$ & 2 \\
$10^{\text {th }}-14^{\text {th }}$ & $<1$ \\
$14,000+$ & $1-3$ \\
\hline
\end{tabular}

Vocabulary knowledge of the $1 \mathrm{k}$ is of great importance for learners of English because they make up such a large percentage of the language, more than any other frequency band. However, knowledge of these words alone is not sufficient for an adequate level of comprehension while reading or listening. Considering the lexical coverage provided by different word frequency lists, to achieve the $95 \%$ lexical coverage of the running words in a text required for adequate comprehension, students need a receptive vocabulary of 3,000 word families. Numerous researchers have argued that a vocabulary size of these 3,000 word families is the minimum threshold in order for learners to communicative and successfully engage in either receptive or productive language use (e.g., Li \& MacGregor, 2010; Schmitt et al., 2015). Without mastery of these words, students' inadequate vocabularies will indeed hinder their performance, directly affect their ability to understand texts, and impair their ability to operate successfully in a language (Alderson \& Banerjee, 2002; Gyllstad Vilkaite \& Schmitt, 2015; Harji et al., 2015; Romer, 2011). Schmitt (2000) makes the important point that "the learning of these basic words can not be left to chance, but should be taught as quickly as possible because they open [...] the door of further learning (p. 137)" and Gallego and Llach, (2009) emphasis that the sooner these words are learnt, the better students' performance will be. As such, students should do all they can to acquire these words and increasing their vocabulary size is ultimately the "principal" task the language learner faces (Milton, 2013, p. 58).

\subsubsection{Academic Word List}

Academic words are those that occur in a high proportion in all academic texts. Academic words comprise approximately $10 \%$ of the words in any academic text (Coxhead, 2000). The Academic Word List (AWL) was compiled from a corpus of 3.5 million running words of written academic text from four faculty sections (Arts, Commerce, Law, Science) and is based on the range and frequency of words outside the 2,000 most frequently occurring words (Coxhead, 2000). The AWL is comprised of a total of 570 words - words that showed the highest frequency and widest text coverage from this academic corpus irrespective of discipline. It is divided into 10 sub-lists, with 60 word families in each sub-list 1-9 respectively, and 30 word families in sub-list 10 . The 60 words on the first sub-list account for more than one third of the total coverage of the list, with the next 60 words on sub-list 2 providing only half the coverage of the first list. The AWL therefore highlights the words that university students are most likely to encounter in a wide range of academic texts and are therefore of greatest value for them to learn (Coxhead, 2000).

\subsubsection{Common European Framework Reference}

As noted by the Educational Testing Service (ETS, 2015), a score on its own does not provide much indication that a particular criterion has been meet, or a particular proficiency has been reached. To give a test score some meaning in terms of English proficiency it should be related to a particular description of language proficiency (Tannenbaum \& Cho, 2014). The Common European Framework Reference for Languages: Learning, Teaching, Assessment (CEFR) provides "a common basis for describing and discussing stages of language development and the skills needed to reach different levels of language proficiency (TOEFL iBT Research Report, 2008, p. 1)." The CEFR describes language proficiency in reading, writing, speaking, and listening on a 6-level scale, clustered in three bands: A1-A2 (Basic User), B1-B2 (Independent User), and C1-C2 (Proficient User) and "is probably the most influential language framework in the field of second language teaching and assessment articulating a progression of language proficiency (Papageorgiou, Tannenbaum, Bridgeman \& Cho, 2015, p. 1).” The CEFR is "widely accepted as the benchmark against which language tests used across Europe should be 
compared." When test scores are equated with a CEFR level, the test scores can have "socially constructed meanings for teachers and other test-score users" (TOEFL iBT Research Report, 2008, p. 1), which gives the score much more meaning because it clarifies exactly "what candidates with at least that score are likely able to do" (TOEFL iBT Research Report, 2008, p. 1).

Although the descriptions of the different CEFR levels do pay particular attention to vocabulary size, which is expected in light of the abundance of research supporting the indisputable relationship between language proficiency and vocabulary breadth, no actual figures of vocabulary size are provided (Milton, 2010). However, Meara and Milton (2003) have usefully provided a vocabulary size range for each CEFR level. They tested students who took the Cambridge exams at every level of the CEFR and estimated their vocabulary sizes using the XLex tests. Milton and Alexiou (2009) also considered this issue of vocabulary size for corresponding CEFR levels for foreign language learners from a variety of countries learning different languages. Learners came from Spain, Hungary, Greece, and Britain and they were learning English, French and Greek as foreign languages. The two important conclusions they make is that progressively greater vocabulary sizes are associated with the progressively higher CEFR levels which provides validity for the CEFR levels and the assumption upon which they are based that as learners progress through the CEFR levels their foreign language lexicons will increase in size and complexity. Secondly, they concluded similar vocabulary size measurements for the different CEFR levels as those reported by Meara and Milton (2003), thus supporting the reported estimates.

\subsection{Research Questions}

This study seeks to answer the following research questions:

1. Does the IEP develop EFL students' vocabulary size?

2. To what extent does the IEP develop EFL students' vocabulary size?

3. Does the vocabulary acquisition follow the frequency effect?

4. Is the increase in vocabulary size sufficient for students to continue to the next English course?

\section{Method}

\subsection{Context of Study}

The focus of this study is the IEP at a private English-medium university in Lebanon, where English is taught as a foreign language. Students enrolled in the IEP have not met the entry requirements for the standard academic English course (as determined by the university). The objective of this course is to acquaint students with basic knowledge of grammar, writing, reading, and listening skills and thus improve their English proficiency to a level that will enable them to successfully move on to the following English remedial course. Students progress from the IEP, to the $1^{\text {st }}$ English remedial course, followed by the $2^{\text {nd }}$ English remedial course, then to the standard academic English courses. The IEP spans one semester (15 weeks), with 3 hours of instruction every day, five days a week (3hours/week/skill) for a total of 180 hours of instruction. As stated in the syllabus, the objective and teaching methodology of each skill are as follows:

\section{Writing}

Objective: To write a well-structured, effective, and academic paragraph using different methods of development.

Methodology: The newly learned structures are applied creatively in different open - ended oral and written activities. The written activities are geared to different types of paragraph writing. Students will learn to write a well-developed paragraph using Illustration, Definition, Description, Process, Compare/Contrast, and Opinion methods.

\section{Grammar}

Objective: To learn, practice and master the rules of grammar through application in a variety of contexts.

Methodology: The grammatical material is presented though context, including passages, articles and dialogues. The new grammatical presentations of structures are introduced in clear charts, notes and examples. The practice is focused on combining both meaning and form in varied controlled exercises.

\section{Reading}

Objective: To develop vocabulary knowledge, academic reading skills and ability to respond to a variety of comprehension questions. 
Methodology: The reading material is presented through pre-reading exercises in order to prepare the students to think before plunging into the reading text and to become alert to the clues from the titles, pictures, and heading that will help them gain overall ideas of the reading selections. Students are then presented with samples of texts which students are to prepare and study before class to develop their reading and study skills. Through different texts, students are exposed to new words and writing styles.

\section{Listening}

Objective: To actively listen to different types of discourse and be able to take accurate notes from different types of discourse. To improve students' ability to respond appropriately and to use English in academic and social situations

Methodology: The listening material is presented though oral pre- listening activities based on pictures, and reading clues to prepare them to the actual listening. The actual listening is presented either through recorded material or by the instructor. The students are trained to take notes while listening for main ideas and details.

The syllabus provides a lesson-by-lesson break down of what material needs to be covered in every session to ensure consistency of content across all the various sections of the intensive program. Instructors meet regularly to further discuss teaching methodology to be as systematic as possible across all sections of the same program and ensure that there is minimal difference across the different sections. For example, all the reading instructors meet to discuss the best teaching methodology to adopt in order to achieve each learning objective and likewise for the instructors of the other skills. One such example is keeping vocabulary lists in the Reading skill; for every reading task, a vocabulary list is made (in the students' notebooks) where new words are continuously added. Each new entry is defined, synonyms are noted, and a contextualized sentence is written. The syllabus is detailed to such an extent, that each page number and exercise that should be completed in any given session is listed for every session. To further ensure consistency across the different classes of the same course, all instructors meet at the beginning at the semester, half-way through and toward the end of the semester before the final exam to reiterate the main focus of each skill, to agree on which tasks will require more time in terms of projected difficulty, as well as to discuss any difficulties encountered and to ensure consistency of teaching approach with the instructor assuming the role of facilitator in the learning process. Additionally, all exams are prepared and reviewed by all instructors.

Placement into the IEP depends on scores of standardized English entrance exams that all students must take (see Table 2 for cut-off scores). Upon completion of the IEP, university policy assumes that the instruction provided leaves students with improved proficiency in English comparable to the level specified for entrance into the first remedial English course on the international standardized tests.

Table 2. Cut-off scores for admittance into the IEP and the $1^{\text {st }}$ remedial course

\begin{tabular}{lll}
\hline & SAT score & iB-TOEFL \\
\hline IEP & $360-380$ & $64-70$ \\
$1^{\text {st }}$ remedial & $380-430$ & $71-87$ \\
\hline
\end{tabular}

Entrance to English-medium universities depends on scores of English placement/entrance exams and given that English-medium universities in Lebanon have not established a unified policy on admission criteria (Nasser \& Goff-Kfouri, 2008), there is much controversy surrounding this lack of consistent gate-keeper scores on a national level at least. However, Burns (1991), Dooey (1999) and Graham (1987) make the crucial recommendation that universities should make their own decisions concerning cut-off scores and acceptable English language proficiency based on the logic that it is difficult to generalize findings from studies - studies with inherent limitations - and apply the findings to situations and contexts full of unique cultural, social and financial factors.

To give these cut-off scores more meaning, they are benchmarked against the CEFR levels. This will enable comparison between entrance requirements, equivalent CEFR level, and vocabulary size of equivalent CEFR level. This information is summarized in Table 3 below. 
Table 3. University cut-off scores relative to CEFR levels

\begin{tabular}{lllll}
\hline & SAT score & iB-TOEFL & Equivalent CEFR level & iB-TOEFL score of equivalent CEFR level \\
\hline IEP & $36-380$ & $64-70$ & B1 & $42-71$ \\
$1^{\text {st }}$ Remedial & $380-430$ & $71-87$ & B2 & $72-94$ \\
\hline
\end{tabular}

As can be seen with these comparisons, the cut-off score between the two courses IEP and $1^{\text {st }}$ Remedial (for the iB-TOEFL equivalent score) is only one point different from the cut-off score between the B1 and B2 level thus making this comparison and equivalence more viable; there is no overlap and the entrance requirements as determined by the university can be unambiguously equated to B1 and B2 CEFR level respectively.

Students placed in the IEP are at the B1 CEFR level given that their test score clearly falls within the upper bound of this range, and likewise, students placed in first remedial course clearly fall within the B2 CEFR level. Again, their scores fall within the range provided albeit at the lower end. It should also be noted that the CEFR B2 level which is the requirement level of the first remedial English course is "the most common requirement for admissions into European universities (Carlsen \& Deygers 2014; cited in Papageorgiou et al., 2015) and "is often acknowledged as the standard for admission into higher education (p. 1)" thus indicating the university's appropriateness of decision regarding entrance requirements.

\subsection{Participants}

Participants were 100 first-year university students (Lebanese, male and female) who were placed in the IEP. They represent close to $50 \%$ of the total number of students enrolled in the IEP during this semester. They did the pre-test at the beginning of the semester and post-test at the end of the semester. The mean age is 18.5 (range 17-22). Participation in the study was voluntary and test results were not included in any course assessment. The informed consent and approval of the university was obtained via the IEP course coordinator after clarification of the purpose, methodology and objective of this research study.

The sample was homogeneous with regards to type and hours of instruction received. As previously noted, all instructors meticulously follow the same syllabus which outlines what needs to be covered on a lesson by lesson basis, and as much as possible, the same teaching methodology. Moreover, all students share the same mother tongue, Arabic, come from a French-medium high school, and are of a similar English proficiency given that they were all placed into the IEP program. For most students, exposure to English outside the classroom is limited and thus so are the opportunities to use English (Al-Khatib, 2013; Yazigi, 1994).

Participants completed the New Vocabulary Levels Test as the pre-test at the beginning of the semester before instruction began and again as the post-test at the end of the semester before the final exam. The test was administered in the classroom by the instructor. For both tests, participants were assured of the confidentiality and anonymity of results and procedures were explained thoroughly. Students were implored to be as honest as possible and not to guess the meaning of a word to reduce the effects of guessing; if they have no knowledge of the correct answer, they should skip the question. Attention was drawn to the example question provided on the first page of the test to encourage understanding of the test format. Also, students were informed that participation would not affect their grades and they were not obliged to partake. The test took approximately 40 minutes to be completed.

\subsection{Instruments}

\subsubsection{The NVLT}

Students' vocabulary breadth was assessed pre and post instruction by means of the New Vocabulary Levels Test (NVLT). The NVLT is a measure of receptive vocabulary knowledge of the most frequent 5,000 word families in Nation's (2012) BNC/COCA word list and Coxhead's (2000) AWL. This test, which is an improved version of the Vocabulary Levels Test (VLT) - the best known and most widely used vocabulary test (Read, 2007; Schmitt, Schmitt \& Clapham, 2001; Webb \& Sasao, 2013) created by Paul Nation (Nation, 1983) and later updated, revised and made more reliable by Schmitt et al. (2001) - measures the degree of mastery of words at different frequency levels and the AWL.

The NVLT addresses the three main limitations of the VLT.

The first limitation of the VLT is that it measures vocabulary knowledge of the most frequent 2000, 3000, 5000, 10,000 word families, as well as academic vocabulary, but does not test knowledge of the most frequent 1000 word families (McLean \& Kramer, 2015; Webb \& Sasao 2013). Given the great importance of these high frequency words for learners of English, their absence from the test is a major drawback. It is essential that 
students have knowledge of these words which make up such a large percentage of the language, more than any other frequency band and thus the importance of measuring such knowledge is invaluable to instructors and program designers. Accordingly, the NVLT sought to overcome this limitation. Furthermore, the NVLT excluded testing knowledge of the 10,000 word level in light of the fact that "mastery of the 5000 word level may be challenging for all but advanced learners, so assessing knowledge at the five most frequent levels may represent the greatest range in vocabulary learning for the majority of L2 learners (Webb \& Sasao, 2013, p. 266)". This is particularly appropriate for this study considering that the subjects are not "advanced" learners and as Read (2007) states, lower frequency words, such as those in the 10,000 list are not at all likely to be known by learners of English in a foreign language environment. Furthermore, McLean and Kramer (2015) showed that for students with low proficiency in English, as is the case for the subjects of this study, most correct answers for the lowest frequency bands can be attributed to chance and not lexical knowledge. As a result, reducing the possibility of score inflation makes the results of the NVLT more accurate and more pedagogically valuable than the results of the VLT (McLean \& Kramer, 2015).

Although students admitted in the IEP would not be expected to know the relatively lower frequency words on the 4 and 5,000 word list, participants were asked to complete the entire test in light of Beglar's (2010) recommendation:

In order to arrive at reasonably precise estimates of vocabulary size, learners should be asked to sit at least two levels beyond their present level because although frequency level is strongly related to the likelihood of a word being known, other factors, such as part of speech, word length, and loan word status, are involved in lexical acquisition (p. 114).

The second limitation of the VLT is the outdated lists used for the different frequency levels. As noted by Webb and Sasao (2013), West's (1953) General Service List was used to create the 2000 word level, and frequency criteria from Thorndike and Lorge (1944) and Kučera and Francis (1967) were used to create the 3000, 5000, and 10,000 word lists. The frequency of occurrence of some words may likely have changed over the last 50 to 70 years. Addressing this limitation, the NVLT uses more recent corpora "allowing teachers to measure knowledge of vocabulary which would be considered much more appropriate for language learners today (McLean \& Kramer, 2015, p. 3)." Notwithstanding Read's (2007) noteworthy point that "it is difficult to find the "perfect" word frequency list to provide a suitable sample of lexical items (p. 112)", the tested words of the NVLT come from Nation's (2012) BNC and COCA word lists. The first and second 1,000-word family lists of the BNC/COCA were derived from a 10 million token corpus that consists of 6 million tokens from spoken British and American English. Having the high frequency lists based on a greater proportion of spoken text means that these words are "appropriate for English as a foreign language teaching and course design (Webb \& Sasao, 2013, p. 267)." The remaining three word family lists, (3000-5000) were based on BNC/COCA word frequency rankings after items from the first two lists were excluded. As Webb and Sasao (2013) state, "the new BNC/COCA lists should be representative of current English and provide a far better indication of the vocabulary being used by native speakers today than the lists used for the creation of the earlier versions of the VLT (p. 267)."

The third limitation of the VLT concerns the test format and the presence of item independence, which exists when the responses to different test items are not dependent on each other (McLean \& Kramer, 2015). The format of the VLT format provides test-takers with six answer choices to be matched with the three target word definitions, as each target word is answered, the number of available options to answer the second and third target word decreases by means of elimination. As such, several researchers including Culligan (2015) and Kamimoto (2014) as well as Beglar and Hunt (1999) comment that it yet to be proven that the assumption of item independence holds true given the test format of the VLT. Also, according to McLean and Kramer (2015), the format of the VLT is "problematic" in terms of actually administering the test because explaining the testing procedure takes time and can be confusing for the test-taker. On the other hand, the NVLT employs a standard multiple-choice format, which is a more accurate way to measure vocabulary knowledge and also satisfies item independence, a prerequisite for test analysis (Kremmel, 2015).

Furthermore, in terms of interpretability of scores, Stewart and White (2011) found that the format of the VLT with 6 options and no item independence is likely to inflate scores by $16.7 \%$ for most levels of ability, while Kamimoto (2008) found that for low-proficiency test-takers mean scores could be inflated by as much as $45 \%$ on the 3,000 frequency level. Thus, the NVLT decreases the chance of score inflation with the varied format. 


\subsubsection{Test Structure}

This test comprises of 6 sections. Sections one to five measure learners' receptive vocabulary knowledge at the 1000, 2000, 3000, 4000, and 5000 word frequency levels respectively, and section six measures receptive vocabulary knowledge of the AWL. There are 24 items per 1000-level, and 30 items for the AWL, for a total of 150 items. The standard 4-option multiple-choice answer key is used (three distractors and one correct answer). This standard format is one in which the test-takers are already familiar with; it is clear, straightforward and unambiguous and thus eases the administrative aspect of the test. Gyllstad et al. (2015) note that "multiple choice tests have a long and time-honored history in language assessment in general (p. 277)" with the main advantages being their ease and objectiveness of scoring, and the ability to test a large number of words in a relatively short period of time (McLean \& Kramer, 2015).

The following is an example of a 1,000 word level item: each selected target item is presented in a context sentence.

time: They have a lot of time.

a. money

b. food

c. hours

d. friends

\subsubsection{Selection of Target Items}

Items were created through retrofit and redesign of VST items. The items on the VST were validated with EFL Japanese university students (Beglar, 2010) and the creators of the NVLT deemed that this validation made them appropriate for the NVLT which was also piloted with a similar group (McLean \& Kramer, 2015). Item specifications were reverse engineered from previous test descriptions and specification-driven test assembly was implemented in line with Fulcher and Davidson (2007) when retrofitting items from 3 monolingual VST versions. Items were reassigned to their appropriate $\mathrm{BNC} / \mathrm{COCOA}$ levels.

\subsubsection{Context Sentence}

Items are presented in bold within a context sentence which is as contextualized as possible without giving hints to the meaning of the target word and which uses words from the first 1,000-word level (for the first 2 lists) whenever possible and from the first two 1,000-word level for lists 3 and above. Accounting for conflation of the construct of L2 lexical inferences with vocabulary knowledge, the context sentences for each item were piloted using pseudo words in place of the target words. If the participants were able to identify the correct answer without seeing the target word, the context sentence was edited as necessary. Items selected for the AWL followed a similar item specification procedure. Using a random number generator three target words were chosen from lists 1-9 and two were chosen from the $10^{\text {th }}$ list. To ensure an even distribution of items, the $30^{\text {th }}$ item was randomly chosen from the entire list (McLean \& Kramer, 2015).

\subsubsection{Answer Options (a-d)}

The answer key was randomly generated; gender-biased language was avoided with balanced gender representation. Distractors were also of similar word frequency as the target word; whenever possible distractors for the first two lists were taken from the first 1,000-word list and for lists three and above from the first two 1,000 -word list whenever feasible. As much as possible, all distractors are equally plausible in the context sentence and piloting was conducted to confirm this. In the cases where a distractor was not plausible, the distractor was replaced with randomly chosen words until all criteria were satisfied (McLean \& Kramer, 2015)

Despite the NVLT addressing these limitations of the VLT, there remains one limitation of employing the NVLT in this study: the similarity of the pre and post tests. Although there was a 15-week gap between administering the two tests, there is still the possibility that students learned and retained from the pre test, which would have affected their scores in the post test.

\section{Results}

Comparison of the NVLT pre test scores with the post test scores reveals that the post test results $(\mathrm{N}=100)$ are associated with numerically larger means for all the word frequency lists and the AWL. The results are summarized in Table 4. 
Table 4. Descriptive statistics for pre and post test scores $(n=100)$

\begin{tabular}{lllllll}
\hline & $1-\mathrm{K}$ & $2-\mathrm{K}$ & $3-\mathrm{K}$ & $4-\mathrm{K}$ & $5-\mathrm{K}$ & AWL \\
\hline Number of test items & 24 & 24 & 24 & 24 & 24 & 30 \\
Pre test mean (SD) & $21.40(3.86)$ & $16.98(4.36)$ & $12.98(4.28)$ & $10.46(4.78)$ & $10.26(4.20)$ & $12.06(6.43)$ \\
Post test mean (SD) & $22.64(1.70)$ & $18.93(3.95)$ & $15.34(3.97)$ & $13.15(4.74)$ & $13.13(4.15)$ & $17.17(5.60)$ \\
\hline
\end{tabular}

Figure 1 is a display of the difference and the improvement made on the post test at each frequency level and the AWL.

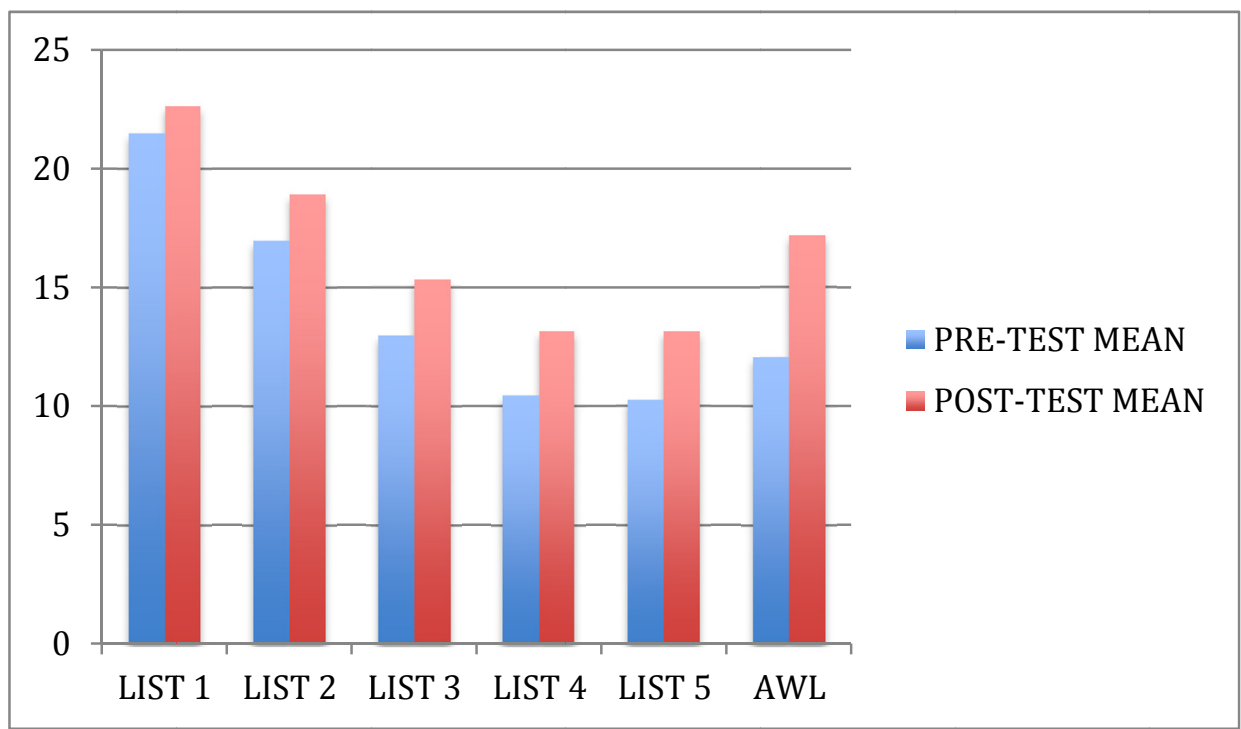

Figure 1. NVLT Pre and post means for various word frequencies $(1,000-5,000)$ and the AWL

To determine if these differences are due to chance or an actual affect in the population and thus to test the hypothesis that pre and post test results on the NVLT were associated with statistically better results, a dependent samples t-test was done. Given the large sample size $(\mathrm{N}=>30)$, the sampling distribution of the mean can be safely assumed to be normal and robust to the normality assumption (Mordkoff, 2016; Martz 2016). The similar values of the standard deviations as shown in Table 1 indicate that the distribution of scores around the means are similar for the pre-test and post-test except for list 1. There are no significant outliers and Cohen's $d$ was estimated at medium for word list 1 and large for word lists 2, 3, 4, 5 and the AWL based on Cohen's $d$ (1992) guidelines. As seen in Table 5 below, the dependent samples t-test confirms that the difference in mean scores between pre and post test for all word levels and the AWL is statistically significant and not by chance. Thus, students' receptive vocabulary breadth at all tested levels was positively and significantly affected by the instruction they received in the IEP.

Table 5. Dependent samples t-test results

\begin{tabular}{lllll}
\hline & Mean & $\mathrm{t}$ & df & Sig (2-tailed) \\
\hline List 1: (Pretest-posttest) & -1.24 & -5.30 & 99 & $0.000^{*}$ \\
List 2: (Pretest-posttest) & -1.95 & -23.40 & 99 & 0.000 \\
List 3: (Pretest-posttest) & -2.36 & -35.79 & 99 & 0.000 \\
List 4: (Pretest-posttest) & -2.69 & -30.43 & 99 & 0.000 \\
List 5: (Pretest-posttest) & -2.87 & -29.25 & 99 & 0.000 \\
AWL: (Pretest-posttest) & -5.110 & -38.792 & 99 & 0.000 \\
\hline
\end{tabular}

* correlation is significant at the 0.05 level (2-tailed). 


\section{Discussion}

\subsection{The IEP and EFL Students' Vocabulary Size}

For all word levels and the AWL, the mean results of the post test are statistically significantly higher than the mean results of the pre test which indicates that students' receptive vocabulary breadth increased post instruction. With the "very strong association between a learner's vocabulary size, and in particular the number of words a learner recognizes in written form, and the communicative level and performance the learner attains (Milton, 2010, p.218)", the larger vocabulary size of the IEP students' post instruction means that their performance and skill in the foreign language has improved. That is, the IEP in this foreign language context has positively impacted students' proficiency in English and results lend support for the effectiveness of this course.

These results are in line with other studies that have assessed IEPs and found favorable results. Zhang and Lu (2014), in a study on 300 first year university students in China, had similar outcomes with statistically significant increases in mean scores at each of the word frequency levels $(2,000 ; 3,000 ; 5,000$ and 10,000) and the AWL, indicating the increase in participants' vocabulary breadth. Similarly, Mukundan et al. (2012) who investigated the effect of an IEP on 30 Malaysian secondary school students by comparing pre and post test results of the standard placement test, found that students performed statistically significantly higher on the post test. They concluded that the 4-week IEP improved language proficiency lending further support for the efficacy of intensive programs.

\subsection{The Extent of Vocabulary Breadth Development}

The vocabulary size of students who completed the IEP increased. The exact number of words that were acquired by the students after instruction is calculated in total and also for each frequency level to determine the extent of the improvement in students' vocabulary size. This is summarized in Table 6.

Table 6. Mean number of words students learned per frequency level and in total

\begin{tabular}{lll}
\hline Frequency level & Mean increase in number of words learned & Mean number of words learned per level* \\
\hline 1000 & 1.24 & 51.6 \\
2000 & 1.95 & 81.1 \\
3000 & 2.36 & 98.2 \\
4000 & 2.69 & 111.9 \\
5000 & 2.87 & 119.3 \\
AWL & 5.11 & 97.1 \\
Total & & $\mathbf{5 5 9 . 2}$ \\
\hline
\end{tabular}

* The mean increase in number of words learned for each frequency level was translated into mean number of words learned for each frequency level by applying Nation's (1990) formula: "Vocabulary size = N correct answers multiplied by total N words in dictionary (the relevant word list) divided by $\mathrm{N}$ items in test" (p. 78).

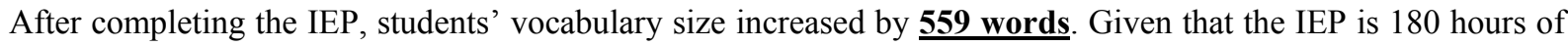
instruction, this equates to 3.1 new words for every contact hour. This rate is concurrent with Milton and Meara's (1998) conclusion that on average, students acquire 3-4 words per contact hour, and higher than the rate of learning found by Milton (2006) for French foreign learners who acquired on average 2.7 words per contact hour. Compared to what is known about the rate of vocabulary growth for native speakers (1,000 words per year), not much is known about the rate of vocabulary growth for non-native speakers (Webb \& Chang, 2012). However, Laufer (1998) gives some indication when she concluded that it takes an L2 learner 6-7 years to have a receptive vocabulary size of 3,500 word families (approximately 500 word families per year) and Schmitt and Meara (1997) who concluded that a learner needs 5-6 years to have a receptive vocabulary size of 3,900 word families (approximately 650 word families per year). Considering the results of these studies, and in light of the research results confirming that knowledge of a word can be assumed to mean knowledge of a word family, the students' improvement of 559 words in one semester ( 15 weeks) is not only in line with the above findings, but it also implies that the IEP is providing an optimal and ideal setting for vocabulary acquisition.

\subsection{The Frequency Effect}

The IEP improved students' vocabulary size by 559 words, at a rate of 3.1 words per hour. Which frequency lists these words actually come from needs to be considered in order to know if students have learnt the words that benefit them the most, or more accurately, if the IEP has exposed students and provided them with the most 
beneficial words. In other words, has the acquisition of vocabulary followed the frequency effect with the more frequent words acquired before the less frequent words?

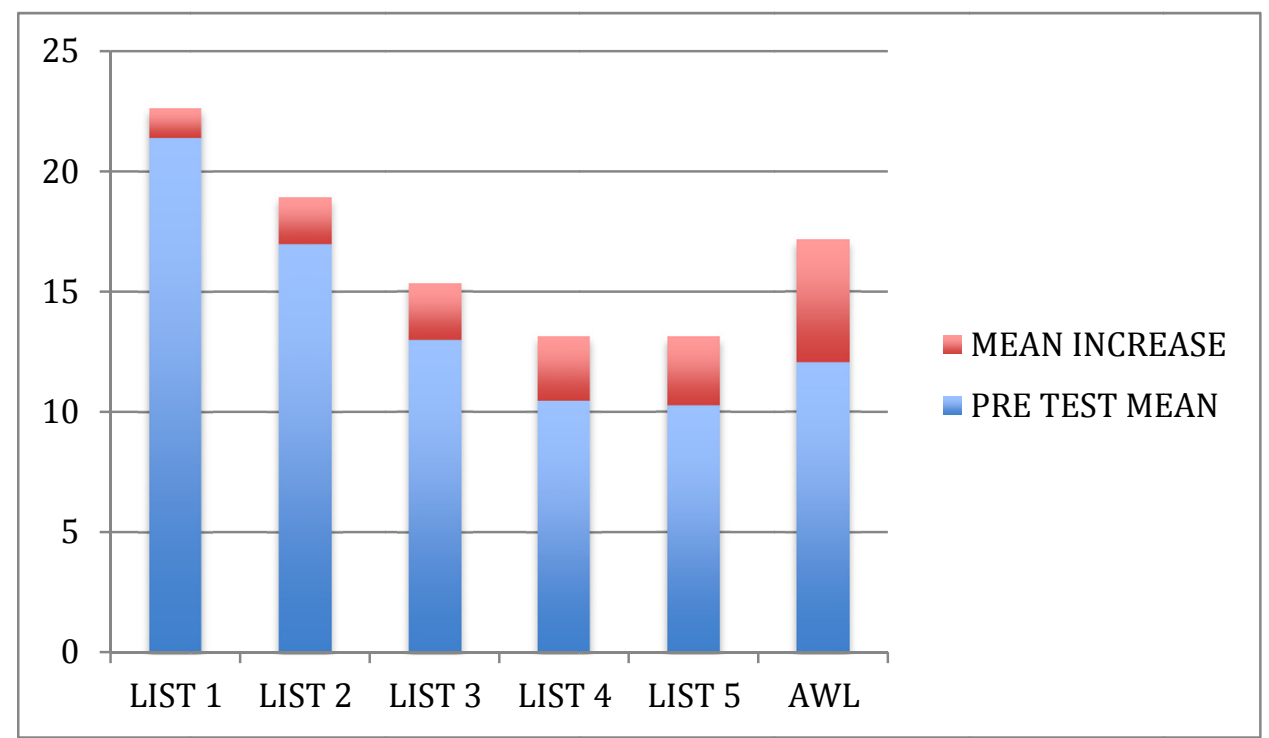

Figure 2. Mean increase in test scores for each word frequency level and the AWL

Figure 2 displays the increase in means for all word frequencies. Clearly, students improved the most on the AWL and the least on List 1. Table 7 provides the percentage increase in each word frequency level.

Table 7. Mean test scores per frequency level pre and post IEP

\begin{tabular}{llll}
\hline Word level & $\begin{array}{l}\text { mean score } \\
\text { (pre) }\end{array}$ & $\begin{array}{l}\text { mean score } \\
\text { (post) } \\
\%\end{array}$ & $\begin{array}{l}\text { change } \\
\%\end{array}$ \\
\hline 1000 & 89.2 & $\underline{94.3}$ & 5.1 \\
2000 & 70.8 & 78.9 & 8.1 \\
3000 & 54.1 & 63.9 & 9.8 \\
4000 & 43.6 & 54.8 & 11.2 \\
5000 & 42.8 & 54.7 & 11.9 \\
AWL & 40.2 & 57.2 & 11.2 \\
\hline
\end{tabular}

The fact that students improved the least on 1000 frequency level (5.1\% improvement) is no surprise given that they already were extremely close to mastery of that word frequency level in the pre test, where mastery is $90 \%$ of a word list (Read, 1988). Thus, there was less room for improvement compared to the other frequency levels. Similarly, the fact that students have not mastered the lower frequency words is also no surprise. As the frequency effect of vocabulary acquisition asserts and as Cobb (2007) states, word families belonging to the frequency levels of +3000 occur so infrequently in texts that students do not meet these words often enough to learn them. While mastery is not expected, results do however imply that students are exposed to lower frequency words suffice for them to have greater improvement in these frequency bands than the higher frequency words. A seen in Table 7, vocabulary breadth knowledge grew at consistently higher rates for the lower frequency words with more improvement on the less frequent words compared to the more frequent words (improvement on 5,000>4,000>3,000>2,000). Of course, this relatively greater improvement on the lower frequency words and the AWL (which is lower frequency given that it incudes words beyond the 2,000 frequency level) is unexpected, yet meaningful especially for the AWL given that the context of this study is a university setting where success in academic English is certainly important.

One explanation for this pattern of vocabulary acquisition is input; the texts and materials students are exposed to in the IEP may contain more academic and less frequently occurring words. Laufer and Ravenhorst-Kalovski (2010) note that it may be possible that some lower frequency words are the key words of an academic text. The 
results suggest that the frequency of words in this learning context is impacting students' acquisition of vocabulary more than the general word frequency. However, research from Waring and Takaki (2003) shows that students do not in fact learn significant vocabulary from reading alone (an average rate of one word per hour of reading), and Laufer (2003) similarly questions whether EFL learners can in fact learn vocabulary through reading. She notes that teachers may have the greatest influence on vocabulary learning, making the following analysis more apt: instructors of this IEP are teaching words of lower frequency and from the AWL before those of a higher frequency. As such, students are acquiring the less frequent words before mastery of the more frequent words which is not the ideal teaching strategy and certainty not the most beneficial for students.

The results of this study are in line with Zhang and Lu's (2014) study. They found that students' vocabulary improved more on the 5,000 level than on the 3,000 and 2,000. Similar to the participants of this study, the Chinese students already had mastery of the lowest frequency level tested $(2,000)$ and thus showed the least improvement. Likewise, Webb and Chang (2012) study on 222 EFL learners in Taiwan found that the increase in students' knowledge of the lower frequency words $(3,000$ and 5,000) was greater than the higher frequency words $(1,000$ and 2,000). They concluded that this represented "inefficient learning" but at the same time that it should be expected in light of the input because "few materials and topics consist entirely of high frequency words (p. 121)."

The findings of this study indicate that students have only mastered the 1,000 word frequency level. Despite their importance, mastery of the $1 \mathrm{k}$ is not enough for functional language proficiency (Groot, 2000) - knowledge of the most frequent 3,000 word families is considered a minimum requirement to achieve success in language learning (Laufer, 1992; Nation, 2001) as this vocabulary size provides students with $95 \%$ lexical coverage necessary for minimum comprehension (Laufer, 1989). Thus, the students of this IEP do not yet have an adequate vocabulary and this will hinder their performance, directly affect their ability to understand texts, and impair their ability to operate successfully in a language (Alderson \& Banerjee, 2002; Gyllstad et al., 2015; Harji et al., 2015). Results reveal that the IEP did improve students' vocabulary size, but not where it is needed. With the effort that is expended by students and instructors alike to improve students' vocabulary size and provide the optimal conditions for acquisition of new words, it is unfortunate that the results show the improvement that is made, is not where it should be.

This crucial decision of what words to teach is indeed challenging, particularly in a foreign language context where the input provided in the classroom is essentially the main source of exposure to the target language (Serrano, Stengers, \& Housen, 2015). While analysis of results of a study such as this in a foreign language context does have the advantage of providing greater control in determining the causes of results (Serrano et al., 2015), the context itself makes the decision of syllabus designers all the more important and their decisions more impact-bearing on the outcomes. That is, as opposed to English as a second language contexts, making decisions of what words are worth focusing on and teaching in an EFL context given the lack of input and the limited class time is challenging, paramount and only amplifies the need for explicit teaching of vocabulary (Laufer, 1994; cited in Gallego \& Llach, 2009). Furthermore, considering the individual differences in students' environment and exposure to English outside the classroom, the fact that they all have such a small vocabulary, which can be safely assumed by their very admittance into the intensive program and as the pre test confirms, means that even if they are exposed to English outside the classroom, it is not comprehensible and therefore will not aid them in any way in expanding their vocabulary (Folse, 2010). By extension, exposure to any English outside the classroom can therefore not impact or have any bearing on the results of this study.

\subsection{Are Students Now Ready for the Next Remedial English Course?}

Whether or not these students are now ready for the $1^{\text {st }}$ remedial English course is determined by considering their vocabulary size pre-instruction and their vocabulary size post-instruction and benchmarking it to the vocabulary size equivalent to the B1 and B2 CEFR levels.

As previously note, the IEP is equivalent to the CEFR B1 level, and the $1^{\text {st }}$ remedial is equivalent to the CEFR B2 level. Using Meara and Milton's (2003) vocabulary size range for each CEFR level, Table 8 reports the vocabulary size of the two CEFR levels. At the B1 level, students have a vocabulary size range of 2,750-3,250. Thus it would be expected that pre-instruction the vocabulary size of students falls within this range. Likewise, upon completion of the program, it is expected that the IEP has improved students' vocabulary size to the 3,250-3,750 range in order for them to be considered at the B2 level. If so, then by extension, if students were to sit the entrance exam again post IEP, they would be placed in the $1^{\text {st }}$ remedial course as their proficiency in English as determined by their vocabulary size has improved to this level. 
Table 8. University course, equivalent CEFR level, and vocabulary size for CEFR level

\begin{tabular}{lll}
\hline Course & Equivalent CEFR levels & $\begin{array}{l}\text { Vocabulary size of CEFR levels } \\
(\max \text { of } 5,000)\end{array}$ \\
\hline IEP & B1 & $2,750-3,250$ \\
$1^{\text {st }}$ Remedial & B2 & $3,250-3,750$ \\
\hline
\end{tabular}

The following tables calculate students' vocabulary size pre and post IEP in order to make the necessary comparison.

Table 9(a). Vocabulary size pre instruction (Meara \& Milton, 2003)

\begin{tabular}{lllllll}
\hline Frequency level & 1,000 & 2,000 & 3,000 & 3,000 & 5,000 & TOTAL=2998 \\
\hline Words known & 890 & 706 & 638 & 435 & 427 & \\
\hline
\end{tabular}

The vocabulary size of 2,998 falls within the range of the B1 vocabulary size.

Table 9(b). Vocabulary size post instruction (Meara \& Milton, 2003)

\begin{tabular}{lllllll}
\hline Frequency level & 1,000 & 2,000 & 3,000 & 3,000 & 5,000 & \\
\hline Words known & 942 & 787 & 638 & 547 & 546 & TOTAL $=\mathbf{3 4 6 0}$ \\
\hline
\end{tabular}

After completing the IEP, students have a vocabulary size of 3,460 which falls within the range of the B2 vocabulary size. These vocabulary sizes with their corresponding CEFR level are summarized below:

Table 10. Vocabulary size pre and post instruction and corresponding CEFR level and university course

\begin{tabular}{llll}
\hline & Vocabulary size & Corresponding CEFR level & Corresponding course \\
\hline Pre-instruction & 2998 & B1 & IEP \\
Post-instruction & 3460 & B2 & Remedial 1 \\
\hline
\end{tabular}

Students complete the intensive course with a vocabulary size associated with the required CEFR level for placement into the first remedial course. Given that the CEFR is considered a tool for informing decisions about levels of English-language proficiency (Papageorgiou et al., 2015), it can be said that the IEP has improved students' proficiency in English to the required level; post IEP, students' level of English proficiency as determined by vocabulary size is congruent to that of students initially placed into the $1^{\text {st }}$ remedial course.

\section{Conclusion}

The research concerning intensive programs in general has yielded conflicting results and as such, whether or not such time-shortened courses are effective in achieving their learning objectives is a matter of controversy. This study hopes to contribute to the current body of research available and perhaps aid in clearing the uncertainty surrounding such compact programs in a foreign language context by evaluating the effectiveness of one IEP through vocabulary size testing.

The results of this study are particularly relevant for other English medium universities in Lebanon given that IEPs are offered at every such institution. As noted by Nasser and Goff-Kfouri (2008), there is a severe lack of research concerning what such programs actually achieve and to date no study has assessed their effectiveness despite their present demand and essentiality. Without assessing the instructional effectiveness of the IEP in its ability to improve students' proficiency in the English language so that they are ready to take on the next English course, we cannot determine the cause for the sentiment that is echoed by one too many faculty members that students, despite completing the IEP, are still not up to standard academically, nor can we make recommendations for improvement to syllabus design and input.

Results show that this IEP is effective in improving students' English language proficiency as measured by the increase in their receptive vocabulary size, in line with the conclusions of many other studies on the effectiveness of intensive programs (Bédard \& Thomas, 2010; Burton \& Nesbit 2002; Carson \& Kuehn, 1992; Daniel 2000; Grant, 2001; Hong-Nam \& Leavell, 2006; Jacques-Bilodea, 2010; Kops, 2014; Nagano, 1995; Ping, 2014; Spade \& Lightbrown, 1994). Over a period of 15 weeks, students' vocabulary size grew by 559 words and 
they advanced from the CEFR B1 level to the CEFR B2 level, which is equivalent to the level necessary for entrance into the next remedial English course of this university.

\subsection{Recommendations}

However, the results also reveal that student's vocabulary knowledge does not provide them with $95 \%$ lexical coverage necessary for reading comprehension and this may hinder their ability to cope with academic studies. With this understanding of students' vocabulary size, appropriate revisions in the syllabus can be made concerning the type and frequency of words acquired to ensure that the necessary opportunities for academic success are available, enhanced and appropriate. Thus, the matter that this IEP must now consider is where the improvement in vocabulary was made and why. Yes, their vocabulary size did increase, and yes their improvement now places them at the B2 CEFR level, and yes they are ready for the next remedial English course in terms of vocabulary size and iB-TOEFL grades. Students are learning new words, but not the words that they need the most. Thus, this study has shown that intensive programs can be successful and also that this particular intensive program needs to consider the results of corpus-based research in its syllabus design. With the increase in vocabulary size exhibited, it is clear that students are increasing their receptive vocabulary breadth, but the choice of words students are exposed to need to be revised. The greater value of the high frequency words to learners dictates that such words should be the focus.

Wilson (2007) makes instructional design recommendations for intensive courses and highlights a notion which can be extremely useful for a foreign language learning situation such as this where there is a limited number of contact hours, limited exposure to the target language and where vocabulary learning needs to be optimized (Webb \& Chang, 2012). It is the notion of prioritized learning, distinguishing between "must knows" (prerequisite knowledge and foundational ideas), "need to knows" (less critical at the moment, but need to know later), and "nice to knows" (can be put off without jeopardizing baseline knowledge).

While increasing breadth of vocabulary knowledge of the lower frequency word families is a "must know" for 98\% coverage (Nation, 2006), it is not a "must know" for 95\% coverage. The low-proficiency students in this program need to master the 3,000 most frequent word families first and this should be the baseline from which all syllabus design decisions are made. Words from the highest frequency word levels that have not yet been mastered are the "must knows".

By building student's breadth of knowledge of the more frequent word families they will be equipped with what they need to prosper in their language learning. Research is continuously reaffirming the correlation between vocabulary size and performance and endorsing this integral relationship between developing a learner's vocabulary knowledge in order to develop his/her performance in the target language (Milton, 2013). Although this IEP does provide vocabulary instruction in the Reading section, which particular words should be learned needs to be indicated in the curriculum (Milton, 2013), and this requires paying more attention to the results of corpus-based research in making such decisions.

\section{References}

Alderson J. C., \& Banerjee, J. (2002). State of the art review: Language testing and assessment (Part Two): State of the art review. Language teaching, 35(2), 79-113. https://doi.org/10.1017/S0261444802001751

Alderson, J. C. (2005). Diagnosing foreign language proficiency: The interface between learning and assessment. London: Continuum.

Al-Khatib, H. (2013). Can universal linguistic fundamentals contribute to the interpretation of EFL learning? European Scientific Journal, 9(35), 28-47.

Bacha, N., \& Bahous, R. (2011). Foreign language education in Lebanon: A context of cultural and curricular complexities. Journal of Language Teaching and Research, 2(6), 1320-1328. https://doi.org/10.4304/jltr.2.6.1320-1328

Bateson, D. (1990). Science achievement in semester and all- year courses. Journal Research in Science Teaching, 27, 23-40. https://doi.org/10.1002/tea.3660270306

Bedard, F., \& Thomas, L. (2010). Impact des politiques linguistiques du Québec sur le développement de l'enseignement de l'anglais, langue seconde. Unpublished Master's Thesis, Université de Sherbrooke, Sherbrooke, Canada.

Beglar, D. (2010). A Rasch-based validation of the Vocabulary Size Test. Language Testing, 27(1), 101-118. https://doi.org/10.1177/0265532209340194

Beglar, D., \& Hunt, A. (1999). Revising and validating the 2000 Word Level and University Word Level 
vocabulary tests. Language Testing, 16(2), 131-162. https://doi.org/10.1177/026553229901600202

Beglar, D., \& Hunt, A. (2005). Six principles for teaching foreign language vocabulary: a commentary on Laufer, Meara, and Nation's “Ten Best Ideas”. The Language Teacher, 29(7), 7-11.

Burns, R. (1991). Study and Stress among First Year Overseas Students in an Australian University. Higher Education Research and Development, 10(1), 61-77. https://doi.org/10.1080/0729436910100106

Burton, S., \& Nesbit, P. (2002). An analysis of student and faculty attitude to intensive teaching. Paper presented at the celebrating teaching and Macquarie, Macquarie University.

Buzash, M. D. (1994). Success of two-week intensive in program in French for superior high school students on a university campus. Paper presented at the Annual Meeting of the Central State conference on the Teaching of Foreign Languages, Kansas City, MO.

Carson, J. E., \& Kuehn, P. A. (1992). Evidence of transfer and loss in developing second language writers. Language Learning, 42(2), 157-182. https://doi.org/10.1111/j.1467-1770.1992.tb00706.x

Ciccarelli, A. (2001). IELTS issues for UniSA. Unpublished paper for Senior Management Group, University of South Australia, Adelaide.

Cobb, T. (2007). Computing the vocabulary demands of L2 reading. Language Learning and Technology, 11, 38-63.

Coxhead, A. (2000). A new academic word list. TESOL Quarterly, 34(2), 213-238. https://doi.org/10.2307/3587951

Culligan, B. (2015). A comparison of three test formats to assess word difficulty. Language Testing, 32(4), 503-520. https://doi.org/10.1177/0265532215572268

Daniel, E. L. (2000). A review of time-shortened courses across disciplines. College Student Journal, 34, 298-308.

Davies, M. (2006). Intensive teaching formats: A review. Issues in Educational Research, 16(1), 1-20.

Decarrico, J. S. (2001). Reading for academic purposes: Guideline for the ESL/EFL teacher. In M. C. Murcial (Ed.), Teaching English as a second or foreign language. Boston, MA: Heinle \& Heinle.

Diab, R. (2006). University students' beliefs about learning English and French in Lebanon. System, 34, 80-96. https://doi.org/10.1016/j.system.2005.06.014

Dooey, P. (1999). An investigation into the predictive validity of the IELTS Test as an indicator of future academic success. In Martin, Stanley \& Davison (Eds.), Teaching in the Disciplines/Learning in Context (pp. 114-118). Proceedings of the $8^{\text {th }}$ Annual Teaching Learning Forum, University of Western Australia, February 1999.

El-Dakhs, D. (2015). The lexical collocational competence of Arab undergraduate EFL learners. International Journal of English Linguistics, 5(5), 60-76. https://doi.org/10.5539/ijel.v5n5p60

ETS. (2015). Linking TOEFL iBT scores to IELTS scores $-A$ research report. Princeton, NJ: Educational Testing Service.

Fan, M. Y. (2001). Do students admitted to the university need help with vocabulary? An investigation into the vocabulary needs of Hong Kong students. Asian Journal of English Language Teaching, 11, 69-85.

Feast, V. (2002). The impact of IELTS scores on performance at university. International Education Journal, 3, $70-85$.

Folse, K. (2010). Is explicit vocabulary focus the reading teacher's job? Reading in a Foreign Language, 22(1), 139-160.

Freed, B. F., Segalowitz, N., \& Dewey, D. P. (2004). Context of learning and second language fluency in French: comparing regular classroom, study abroad, and intensive domestic immersion programs. SSLA, 26, 275-301. https://doi.org/10.1017/S0272263104262064

Gallego, M., \& Llach, M. (2009). Exploring the increase of receptive vocabulary knowledge in the foreign language: a longitudinal study. International Journal of English Studies, 9(1), 113-133.

Gallow, M. A., \& Odu, M. (2009). Examining the Relationship between Class scheduling and Student Achievement in College Algebra. Community College Review, 36(4), 299-325. https://doi.org/10.1177/0091552108330902 
Gao, X. (2003). Changes in Chinese students' learner strategy use after arrival in the UK: A qualitative inquiry. In D. Palfreyman \& R. C. Smith (Eds.), Learners autonomy across cultures: Language education perspectives (pp. 41-57). Basingstoke, UK: Palgrave Macmillan. https://doi.org/10.1057/9780230504684_3

Geltner, P., \& Logan, R. (2001). The influence of term length on student success. Research Report 2001. 4.1.0. Santa Monica, CA: Office of Institutional Research, Santa Monica College.

Graham, J.G. (1987). English Language Proficiency and the Prediction of Academic Success. TESOL Quarterly, 21(3), 505-521. https://doi.org/10.2307/3586500

Grant, B. (2001). Using block courses for teaching logistics. International Journal of Physical Distribution and Logistics management, 31(7/8), 574. https://doi.org/10.1108/09600030110402987

Groot, P. (2000) Computer assisted second language acquisition. Language Learning \& Technology, 4(1), 60-81.

Gyllstad, H., Vilkaite, L., \& Schmitt, N. (2015). Assessing vocabulary size through multiple-choice formats. International Journal of Applied Linguistics, 166(2), 276-303.

Harji, M., Balakrishnan, K., Bhar, S., \& Krishnaveni Letchumanan, K. (2015). Vocabulary levels and size of Malaysian undergraduates. English Language Teaching, 8(9), 119-130. https://doi.org/10.5539/elt.v8n9p119

Henbery, K. (1997). The impact of class schedule on student performance in a financial management course. Journal of Education for Business, 73(2), 114. https://doi.org/10.1080/08832329709601627

Hill, K., Storch, N., \& Lynch, B. (1999). A Comparison of IELTS and TOEFL as Predictors of Academic Success. English Language Testing System Research Reports, 2, 52-63.

Hong-Nam, K., \& Leavell, A. G. (2006). Language learning strategy use of ESL students in an intensive English learning context. System, 34, 399-415. https://doi.org/10.1016/j.system.2006.02.002

Jacques-Bilodeau, M. (2010). Research project: A study of the long term effects of Intensive English programs on secondary school ESL students. Retrieved from www.csbe.qc.ca/projetrd/doc_projet/marie_jac_bil_2010.pdf

Jonas, P. M., \& Weimer, D. (1999, May-June). Non-traditional vs. traditional academic delivery systems: Comparing ETS scores for undergraduate students in business programs. Paper presented at the Forum of the association for Institutional Research. Seattle, WA.

Kamimoto, T. (2014). Local item dependence on the Vocabulary Levels Test revisited. Vocabulary Learning and Instruction, 3(2), 56-68.

Kops, W. (2014). Teaching compressed-format courses: teacher-based best practices. Canadian Journal of Continuing Education, 40(1), 1-18. https://doi.org/10.21225/D5FG7M

Kremmel, B. (2015). The more, the merrier? Issues in measuring vocabulary size. Paper presented at the LTRC 2015: The Language Testing Research Colloquium, Toronto.

Kremmel, B. (2016). Word Families and Frequency Bands in Vocabulary Tests: Challenging Conventions. TESOL Quarterly, 50, 976-987. https://doi.org/10.1002/tesq.329

Laufer, B. (1989). What percentage of text-lexis is essential for comprehension? In C. Lauren \& M. Nordman (Eds.), Special Language: From Humans Thinking to Thinking Machines. Clevedon: Multilingual Matters.

Laufer, B. (1992). How much lexis is necessary for reading comprehension? In P. J. L. Arnaud \& H. Béjoint (Eds.), Vocabulary and applied linguistics (pp. 126-132). London: Macmillan.

Laufer, B. (1997). The lexical plight in second language reading: Words you don't know, words you think you know, and words you can't guess. In J. Coady \& T. Huckin (Eds.), Second language vocabulary acquisition (pp. 20-34).

Laufer, B. (1998). The development of passive and active vocabulary in a second language: same or different? Applied Linguistics, 19(2), 255-271.

Laufer, B. (2003). Vocabulary acquisition in a second language: Do learners really acquire most vocabulary by reading? Some empirical evidence. Canadian Modern Language Review, 59, 565-585. https://doi.org/10.3138/cmlr.59.4.567

Laufer, B., \& Ravenhorst-Kalovski, G. (2010). Lexical threshold revisited: lexical text coverage, learners' vocabulary size and reading comprehension. Reading in a Foreign Language, 22(1), 15-30. 
Li, L., \& MacGregor, L. (2010). Investigating the receptive vocabulary size of university-level Chinese learners of English: how suitable is the Vocabulary Levels Test? Language and Education, 24(3), 239-249.

Malvern, D., Richards, B., Meara, P., \& Milton, J. (2008). Introduction: special issue on knowledge and use of the lexicon in French as a second language. French Language Studies, 18, 269-276. https://doi.org/10.1017/S095926950800344X

Martin, H., \& Culver, K. (2007). Concentrate, intensify, or shorten: Short intensive courses in summer session. Continuing Higher Education Review, 71, 90-100.

Matsuoka, W., \& Hirsh, D. (2010). Vocabulary learning through reading: Does an ELT course book provide good opportunities? Reading in a Foreign Language, 22(1), 56-70.

McLean, S., \& Kramer, B. (2015). The creation of a new Vocabulary Levels Test. Shiken, 19(2), 1-11.

Meara, P. (1996). The dimensions of lexical competence. In G. Brown, K. Malmkjaer, \& J. Williams (Eds.), Performance and competence in second language acquisition (pp. 35-53). Cambridge: Cambridge University Press.

Meara, P., \& Milton, J. (2003). X_Lex The Swansea Levels Test. Newbury: Express.

Merikivi, R., \& Pietilä, P. (2014). Vocabulary in CLIL and in mainstream education. Journal of Language Teaching and Research, 5(3), 487-497. https://doi.org/10.4304/j1tr.5.3.487-497

Milton, J. (2006). Language lite? Learning French vocabulary in school. French Language Studies, 16, 187-205. https://doi.org/10.1017/S0959269506002420

Milton, J. (2010). The development of vocabulary breadth across the CEFR levels. In I. Vedder, I. Bartning, \& M. Martin (Eds.), Communicative proficiency and linguistic development: intersections between SLA and language testing research (pp. 211-232). Second Language Acquisition and Testing in Europe Monograph Series 1.

Milton, J. (2013). Measuring the contribution of vocabulary knowledge to proficiency in the four skills. In C. Bardel, C. Lindqvist, \& B. Laufer (Eds.), L2 vocabulary acquisition, knowledge and use: New perspectives on assessment and corpus analysis (pp. 57-78). Eurosla Monographs 2.

Milton, J., \& Alexiou, T. (2009). Vocabulary size and the Common European Framework of Reference for Languages. In B. Richards, H. M. Daller, D. D. Malvern, P. Meara, J. Milton, \& J. Treffers-Daller (Eds.), Vocabulary Studies in First and Second Language Acquisition (pp. 194-211). Basingstoke: Palgrave Macmillan.

Milton, J., \& Meara, P. (1998). Are the British really bad at learning foreign languages? Language Learning Journal, 18, 68-76.

Milton, J., Wade, J., \& Hopkins, N. (2010). Aural word recognition and oral competence in English as a foreign language. In R. Chacón-Beltrán, C. Abello-Contesse \& M. M. Torreblanca-López (Eds.), Insights into Non-native Vocabulary Teaching and Learning (pp. 83-98). Bristol: Multilingual Matters.

Mukundan, J., Mahvelati, E. H., \& Nimehchisalem, V. (2012). The effect of an intensive English program on Malaysian secondary school students' language proficiency. English Language Teaching, 5(11), 1-7. https://doi.org/10.5539/elt.v5n11p1

Mukundan, J., Mahvelati, E. H., \& Nimehchisalem, V. (2013). Malaysian secondary school students' ESL writing performance in an intensive English program. World Applied Sciences Journal, 22(12), 1677-1684.

Nagano, T. (1995). Nohongo no onsei kyoiku - Supichi komyunikeishon (Japanese oral expression education Speech communication).

Nasiri, E., \& N. Shokrpour, (2012). Comparison of intensive and non-intensive English courses and their effects on the student's performance in an EFL university context. European Scientific Journal, 8(8), 127-137.

Nasser, R., \& Goff-Kfouri, C. (2008). Assessment of the English remedial programme at a private university in Lebanon. Mediterranean Journal of Educational Studies, 13(1), 85-100.

Nation, I. S. P. (1990). Teaching and learning vocabulary. New York: Newbury House.

Nation, I. S. P. (2001). Learning vocabulary in another language. Cambridge: Cambridge University Press. https://doi.org/10.1017/CBO9781139524759

Nation, I. S. P. (2006). How large a vocabulary is needed for reading and listening? Canadian Modern Language 
Review, 63, 59-82.

Nation, I. S. P., \& Beglar, D. (2007). A vocabulary size test. The Language Teacher, 31(7), 9-13. Retrieved from http://jalt-publications.org/file/pdf/the_language_teacher/07_2007tlt.pdf

Nicolas, M., \& Annous, S. (2013). Assessing WAC elements in business syllabi. Business Communication Quarterly, 76(2), 172-187. https://doi.org/10.1177/1080569912471709

Papageorgiou, S., Tannenbaum, R., Bridgeman, B., \& Cho, Y. (2015). The association between TOEFL iBT test scores and the Common European Framework of Reference Levels. ETS Research Memorandum Series.

Paul, P. V., Stalman, A. C., \& O'Rourke, J. P. (1990). Using three test formats to assess good and poor reader's word knowledge. Technical Report No. 509 of the Center for the Study of Reading. University of Illinois. Retrieved from http://www.eric.ed.gov/ERICWebPortal/contentdelivery/servlet/ERICServlet?accno=ED322493

Ping, R. (2014). Investigating the efficacy of an intensive English program and the L2 learners' learning style. Advances in Language and Literacy Studies, 5(5), 246-253.

Read, J. (1988). Measuring the vocabulary knowledge of second language learners. RELC Journal, 19(2), 12-25. https://doi.org/10.1177/003368828801900202

Read, J. (1998). Validating a test to measure depth of vocabulary knowledge. In A. J. Kunnan (Ed.), Validation in language assessment (pp. 41-61). Mahwah, NJ: Lawrence Erlbaum Associates.

Read, J. (2007). Second language vocabulary assessment: current practices and new directions. International Journal of English Studies, 7(2), 105-125.

Römer, U. (2011). Corpus research applications in second language teaching. Annual Review of Applied Linguistics, 31, 205-225. https://doi.org/10.1017/S0267190511000055

Schmitt, N. \& Meara, P. (1997). Researching vocabulary through a word knowledge framework. Studies in Second Language Acquisition, 19(1), 17-36. https://doi.org/10.1017/S0272263197001022

Schmitt, N. (2000). Vocabulary in Language Teaching. Cambridge University Press.

Schmitt, N., \& Schmitt, D. (2014). A reassessment of frequency and vocabulary size in L2 vocabulary teaching. Language Teaching, 47(4), 484-503. https://doi.org/10.1017/S0261444812000018

Schmitt, N., Cobb, T., Horst, M., \& Schmitt, D. (2015). How much vocabulary is needed to use English? Replication of Van Zeeland \& Schmitt (2012), Nation, (2006), and Cobb (2007). Language Teaching, 1-15.

Schmitt, N., Schmitt, D., \& Clapham, C. (2001). Developing and exploring the behaviour of two new versions of the Vocabulary Levels Test. Language Testing, 18(1), 55-88. https://doi.org/10.1177/026553220101800103

Schoonen, R. (2010). The development of lexical proficiency knowledge and skill. Paper presented at the Copenhagen Symposium on Approaches to the Lexicon, Copenhagen Business School on 8-10 December 2010 .

Scott, P. A., \& Conrad, C.F. (1992). A critique of intensive courses and agenda for research. Madrison WI: Division of Summer Sessions and inter-college programs, university of Wisconsin.

Serrano, R., \& Munoz, C. (2007). Same hours, different time distribution: Any difference in EFL? System, 35, 305-321.

Serrano, R., Stengers, H., \& Housen, A. (2015) Acquisition of formulaic sequences in intensive and regular EFL programmes. Language Teaching Research, 19(1), 89-106. https://doi.org/10.1177/1362168814541748

Shaaban, K., \& Ghaith, G. (2002). University students' perceptions of the ethnolinguistic vitality of Arabic, French and English in Lebanon. Journal of Sociolinguistics, 6(4), 557-574. https://doi.org/10.1111/1467-9481.00201

Sinno, Z. S. (2008). The impact on language learning of Lebanese students' attitude towards English in the context of globalization and anti-Americanism. Unpublished Doctorate Thesis, University of Leicester, U.K.

Spade, N., \& Lightbown, P. M. (1994). Intensive ESL Programs in Queen Primary School. TESOL Canada Journal, 7, 11-32. https://doi.org/10.18806/tesl.v7i1.557

Stæhr, L. S. (2008). Vocabulary size and the skills of listening, reading and writing, Language Learning Journal $36(2), 139-52$. 
Tannenbaum, R. J., \& Cho, Y. (2014). Critical factors to consider in evaluating standard-setting studies to map language test scores to frameworks of language proficiency. Language Assessment Quarterly, 11, 233-249. https://doi.org/10.1080/15434303.2013.869815

Tatum, B. C. (2010). Accelerated education: learning on the fast track. Journal of Research in Innovation Teaching, 3(1), 33-50.

Vermeer, A. (1992). Exploring the Second Language Learner Lexicon. In L. Verhoeven \& J. H. A. L. De Jong (Eds.), The Construct of Language Proficiency: applications of psychological models to language assessment (pp. 147-171). Amsterdam: John Benjamins.

Waring, R., \& Takaki, M. (2003). At what rate do learners learn and retain new vocabulary from reading a graded reader? Reading in a Foreign Language, 15(2).

Webb, S. A., \& Chang, AC-S. (2012). Second language vocabulary growth. RELC Journal, 43(1), 113-126. https://doi.org/10.1177/0033688212439367

Webb, S. A., \& Sasao, Y. (2013). New directions in vocabulary testing. RELC Journal, 44(3), 263-277. https://doi.org/10.1177/0033688213500582

White, J., \& Turner, C. E. (2005). Comparing children's oral ability in two ESL programs. Canadian Modern Language Review, 61(4), 491-517. https://doi.org/10.3138/cmlr.61.4.491

Wilkins, D. A. (1972). Linguistics and language teaching. London: Edward Arnold.

Wilson, L. O. (2007). When backward is forward thinking: Radical changes in instructional designs for summer school. Presentation at the North Central Conference of Summer Sessions Annual Conference, Chicago, IL.

Wlodkowski, R. J., Iturralde-Albert, L., \& Mauldin, J. (2000). Report on accelerated learning research project: Phase 4. The center for the Study of Accelerated learning, Regis University, School for Professional Studies and New Ventures, Denver, CO.

Yazigi, R. (1994). Perceptions of Arabic as native language and the learning of English. Language Learning Journal, 9, 68-74. https://doi.org/10.1080/09571739485200221

Zhang, X., \& Lu. X. (2014). A longitudinal study of receptive vocabulary breadth knowledge and vocabulary fluency development. Applied Linguistics, 35(3), 283-304. https://doi.org/10.1093/applin/amt014

\section{Copyrights}

Copyright for this article is retained by the author, with first publication rights granted to the journal.

This is an open-access article distributed under the terms and conditions of the Creative Commons Attribution license (http://creativecommons.org/licenses/by/4.0/). 